\title{
Deneme Seyri Planlamasında PERT Uygulaması
}

\author{
Mustafa Kafalı ${ }^{1}$, Yusuf Genç ${ }^{2}$ \\ ${ }^{1}$ İzmir Kâtip Çelebi Üniversitesi, Gemi İnşaatı ve Denizcilik Fakültesi, Gemi İnşaatı ve Gemi Makineleri \\ Mühendisliği Bölümü, İzmir, Türkiye \\ ${ }^{2}$ Ordu Üniversitesi, Fatsa Meslek Yüksekokulu, Gemi İnşaatı Programı, Ordu, Türkiye \\ ${ }^{1}$ (sorumlu yazar), mustafakafali@ikcu.edu.tr, ORCID: 0000-0002-8077-1686 \\ 2 yusufgenc55@yahoo.com, 0000-0002-4903-5015
}

\section{ÖZET}

Bu çalışmada üretim sürecinin sonuna yaklaşmış, fabrika kabul ve liman kabul testleri tamamlanmış olan bir geminin deneme seyri sırasında yapılacak olan testler için bir planlama yapılmıştır. Deneme seyrinde gerçekleştirilen testler ve bunların yaklaşık süreleri gerçek bir deneme seyri gözleminden elde edilmiştir. Çalışmada deneme seyri bir proje olarak ele alınarak öncelikle gerçekleştirilecek testler birer aktivite olarak kabul edilmiş ve liste halinde belirlenmiştir. Daha sonra testleri gerçekleştirecek kişiler kaynak olarak atanmıştır. Bunun ardından testler arasındaki öncül-ardıl ilişkileri incelenerek aynı zaman diliminde yapılabilecek ve birbirlerini etkilemeyecek testler belirlenmiştir. Bu sayede testler için gerekli kaynak atamaları yapılarak uygun bir seyir çizelgesi elde edilmeye çalışılmıştır. Ayrıca elde edilen çizelge kullanılarak deneme seyri için kritik yol tespit edilmiştir. Böylece hangi testlerin kritik olduğu belirlenmiştir. Ayrıca PERT (Program Evaluation and Review Technique) analizi yapılarak deneme seyrinin tamamlanma süresinin beklenen değeri ve standart sapması hesaplanmıştır. Bunun yanı sıra standart z tablosu yardımı ile farklı deneme seyir süresi değerleri için olasılık hesapları yapılmıştır. Burada altı farklı deneme seyir süresi için altı farklı ihtimal değeri belirlenmiştir. Ayrıca hazırlanan seyir çizelgesi ile deneme seyrinde her bir kaynağa düşen iş miktarları ayrı ayrı hesaplanmıştır. Yine buna paralel olarak, hazırlanan çizelge üzerindeki her bir testin iş miktarı da belirlenmiştir. Bu çalışmada yapılmış olan uygulamada olduğu gibi, öncelikle deneme seyrinin planlaması yapılıp bu plana uygun bir şekilde hareket edilerek deneme seyrinin daha başarılı bir şekilde tamamlanabileceği düşünülmektedir.

Anahtar kelimeler: Deneme seyri, PERT, Gemi inşa, Planlama

Makale geçmişi: Geliş 13/08/2021 - Kabul 15/11/2021

https://doi.org/10.54926/gdt.982662 


\title{
PERT Application for Sea Trial Planning
}

\author{
Mustafa Kafalı ${ }^{1}$, Yusuf Genç ${ }^{2}$ \\ ${ }^{1}$ İzmir Katip Çelebi University, Faculty of Naval Architecture and Maritime, Department of Naval Architecture \\ and Marine Engineering, İzmir, Turkey \\ ${ }^{2}$ Ordu University, Fatsa Vocational Higher School, Vessel Construction Program, Ordu, Turkey \\ ${ }^{1}$ (corresponding author), mustafakafali@ikcu.edu.tr, ORCID: 0000-0002-8077-1686 \\ 2 yusufgenc55@yahoo.com, 0000-0002-4903-5015
}

\begin{abstract}
In this study, a planning has been made for the tests to be carried out during the sea trial of a ship, which is near the end of the production process and whose factory acceptance and harbor acceptance tests have been completed. Sea trial tests and their approximate durations are derived from a real sea trial observation. The sea trial was viewed as a project in the study, and first, the tests to be carried out were accepted as an activity and listed. Then, the people who will conduct the tests are assigned as resources. Following that, the predecessor-successor relationships between the tests were investigated, and the ones that could be performed concurrently and without interfering with one another were identified. In this way, the necessary resource assignments for the tests were made and an appropriate sea trial schedule was tried to be obtained. In addition, the critical path for sea trial was determined by using the obtained schedule. Thus, the critical tests were identified. In addition, PERT (Program Evaluation and Review Technique) analysis was performed to calculate the expected value and standard deviation of the completion time of sea trial. Furthermore, probability of the different sea trial completion times are calculated with the help of the standard $z$ table. Here, six different probability values are determined for six different sea trial times. Additionally, with a sea trial schedule prepared, the amount of work falling on each resource during the sea trial was calculated separately. Additionally, the amount of work falling on each resource is calculated separately. As in the practice in this study, it is thought that the sea trial can be completed more successfully by planning the sea trial first and acting in accordance with this plan.
\end{abstract}

Keywords: Sea trial, PERT, shipbuilding, planning

Article history: Received 13/08/2021 - Accepted 15/11/2021 


\section{Giriş}

Dünya ticaretine yön veren gemilerin üretim süreçleri oldukça karmaşık bir yapıya sahiptir. Bu süreçlerin iyi yönetilebilmesi hem tersane hem de armatör açısından büyük önem arz etmektedir. Rekabet ortamının sürekli arttığı günümüz dünyasında, ayakta kalabilmeyi ve üretimde sürekliliği yakalamayı hedef alan işletmelerin ciddi bir titizlik ve planlama ile çalışmaları gerekmektedir. Bunun yanı sıra üretim planlaması açısından yaşanan gelişmeler, sisteme dâhil olan yenilikler takip edilmeli ve ilgili tersanelerde tatbik edilmelidir. İş verimliliğini yüksek tutmak ve başarısını sürdürmek isteyen tersanelerin bu zorluğun üstesinden gelmesi gerekmektedir (Kafalı vd., 2021). Üretimde sürekliliği hedefleyen firmaların geleceği, üretimdeki aktivitelerini yükseltme yeteneklerini ne denli ileriye taşıyabileceklerine bağlıdır (Goldratt ve Cox, 1992). Kaliteden ödün vermeden üretimde artış, ancak sistemler ve uygulamalar üzerinde yapılacak olan iyileştirmelerle sağlanabilir.

Gemi üretiminde küresel ölçekte söz sahibi olmak isteyen tersanelerin, projeleri zamanında teslim etmesi ve müşteri memnuniyetini ön planda tutması gerektiği açıktır. Zamanında teslim performansı armatörlerin göz önünde bulundurduğu en önemli etkenler arasında yer aldığından bu anlamdaki yüksek performans yeni proje anlaşmalarının önünü açacaktır (Kafalı ve Özkök, 2015; Hwang vd., 2014). Bu sebeple teknolojik açıdan çeşitlilik gerektiren bu üretim sürecinin iyi yönetilebilmesi ancak üst düzeyde hazırlanmış planlamalar ile sağlanabilmektedir. Sürekli gözetim ve denetim altında tutulması gereken gemi üretim süreçlerinin en büyük yardımcısı matematiksel modeller yardımı ile oluşturulmuş olan bilgisayar programlarıdır (Abdel-latif vd., 2013). Bu programlar sayesinde yapılan planlamalar yaşanabilecek sorunların daha önceden görülebilmesine yardımcı olmaktadır. Bu sayede üretimde iyileştirmeler yapılabilmekte ve gemi teslim süreçlerine olumlu katkılar sağlanabilmektedir. Öte yandan zamanında teslim edilmiş bir geminin iyi bir planlamanın ürünü olduğu unutulmamalıdır. Ayrıca gemi üretimi konusunda planlamanın personel deneyimine bağlı olduğu düşünüldüğünden, planlama ve verimliliği artırmaya yönelik çok az akademik çalışma olduğu bilinmektedir (Lee vd., 2018; Song vd., 2011).

Gemi üretimi, projenin başlangıç aşamasından başlayarak teslim aşamasına gelene kadar gözetim, denetim altında tutulması gereken ve sistematik bir mühendislik gerektiren zorlu bir süreçtir (Wang vd., 2019; Akan ve Bayar, 2021). Blok üretim, boru donatım, elektrik, izolasyon, teçhiz vb. üretim basamakları tersane personeli, klas ve armatör temsilcilerinin de katıldığı testler ile denetlenmektedir. Bu çalışmada fabrika kabul ve liman kabul testleri başarı ile tamamlanmış olan geminin deneme seyri boyunca uygulanacak olan testlerinin planlanması ele alınmıştır. Deneme seyrinde yapılan test ve tecrübeler gemi tipine bağlı olarak farklıık göstermekle birlikte, Uluslararası Denizcilik Örgütü (IMO) 100 metreden büyük gemilerde seyir tecrübelerinden dönme, zig-zag ve durma manevralarının yapılmasını zaruri görmektedir (IMO Circular, 2002). Geminin teslim aşamasında yapılan bu testler gemide çalışacak personelin gemiyi tanıması açısından da önemlidir.

Deneme seyirleri ve PERT ile ilgili çalışmalar incelendiğinde, Abdel-latif vd. (2013) yapmış oldukları çalışmada Simulink yazılımı ile Esso Osaka tanker sınıfı geminin manevra performansını incelemek üzere hidrodinamik kuvvetler ve momentler oluşturmuşlardır. Dönme ve zig-zag manevra testlerini inceleyerek olumlu sonuçlar elde etmişlerdir. Doğan ve Helvacıoğlu (2017) ise çalışmalarında, gemi inşa Proje Yönetimi Enstitüsü proje yönetimi metodolojisinin kullanımını ve pratikliğini incelemişlerdir.

Genç ve Özkök (2020) deneme seyri ilgili yaptıkları simülasyon çalışmasında toplam seyir süresini kısaltmaya çalışarak iki farklı seyir programı oluşturmuşlardır. Toplam sürenin kısaltılması açısından olumlu sonuçlar elde etmişlerdir. Turan ve Asar (2020) çalışmalarında PERT yöntemi kullanarak tankerin tamir ve bakım sürecini analiz etmişlerdir. Akan ve Bayar (2021) gemi inşaatında proje 
yönetimi için Type-2 bulanık kümeler PERT yöntemi önermişler ve bunu elektrikli bir yatın üretim çizelgesine uygulayarak başarılı sonuçlar elde etmişlerdir. Aktan (1995) yüksek lisans çalışmasında 26300 DWT ve 75000 DWT'lik gemiler için liman ve deniz tecrübelerini incelemiştir. Kaynak kısıtlarını ele almadan gemilerin liman ve seyir testlerinin neler olduğunu açıklamış ve bunlarla ilgili tecrübî olarak bir işlem sırası ortaya koymuştur. Ayrıca intiyaç durumunda bu sıralamanın değiştirilebileceğini belirtmiştir. Fulser (2012) yüksek lisans çalışmasında askeri ve sivil gemi inşaatında test ve kabul süreçlerini incelemiştir. Bu faaliyetler ile ilgili bazı optimizasyon önerilerinde bulunmuştur. Test ve tecrübeler hakkında bir diğer yüksek lisans tezi Aslıyüksek (2013) tarafından hazırlanmıştır. Çalışmada bu faaliyetlerin yönetimsel süreçlerine değinmiştir. Ayrıca yapılacak testlerde personel arasındaki iletişimin önemi vurgulanmıştır.

Bu çalışmada daha önce yapılan kimyasal tanker deneme seyirleri incelenerek deneme seyrinin daha efektif ve sorunsuz olarak tamamlanmasını sağlamak üzere çizelgeleme işlemi gerçekleştirilmiştir. Bu amaçla öncelikle deneme seyri bir proje olarak ele alınmış ve bu projede gerçekleştirilecek aktiviteler (testler) ve bu aktivitelerde kullanılan kaynaklar belirlenmiştir. Burada kaynak olarak klas sörveyörleri, armatör temsilcileri, üretim ve kalite departmanlarından mühendis ve formenler, güverteci ve makineci işçiler, servis mühendisleri tanımlanmıştır. Deneme seyrine ayrıca iş güvenlik uzmanları da iştirak etmektedir. Ancak bunlar seyir süreci üzerinde herhangi bir kısıt oluşturmadıklarından çizelgeleme sürecinde ele alınmamışlardır. Daha sonra her bir test için öncül ve ardıl yapılabilme durumları ve testlerin birbirleri ile olan ilişkileri incelenmiştir. Ayrıca aynı süre içinde yani eş zamanlı olarak yapılabilecek ve birbirini etkilemeyecek testler belirlenmeye çalışılmışır. Daha sonra kaynak kapasitesi göz önünde bulundurularak uygun bir deneme seyri çizelgesi oluşturulmuştur.

\section{Deneme Seyri}

Deneme seyri, tersane ve liman kabul testleri başarı ile tamamlanmış olan geminin armatöre teslim edilmeden önce denenmesi amacıyla gerçekleştirilir. Deneme seyri boyunca uygulanacak olan test ve tecrübeler gemi tipine göre değişebilir. Bu çalışmada irdelenen deneme seyri, açıkta bekleyen geminin draftlarının ölçülmesi ve tüm personelin gemiye çıkmasının ardından başlangıç toplantısı ile başlamaktadır. Bu sırada ilgili personel ile cayro pusula ve ana makine ayarları ile navigasyon ekipman testlerinin yapılması planlanmıştır. MDO'dan (marine diesel oil) HFO'ya (heavy fuel oil) geçiş işleminin yapılmasından önce ana makine ayarları öncül işlem olarak belirlenmiştir. HFO'ya geçiş sonrası geminin yeterli derinlik için açılması ve sonrasında sancak ve iskele baş itici (bow-thruster) testlerinin yapılması öngörülmüştür. Sancak ve iskele demir ve ırgat testlerinin baş itici testlerinden sonra yapılması planlanmıştır. Kazan kontrolleri (boiler controls) ve alarm testleri başlangıç toplantısı tamamlandıktan sonra gerçekleştirilebilir. Ayrıca yakıt hazırlama (booster) modül testi ve alarm kontrolleri için HFO' ya geçiş öncülü yeterli görülmüştür. Bunun yanı sıra seperatör testleri için ise kazan kontrolleri ve başlangıç toplantısı öncül aktiviteler olmuştur.

Ana makine dayanıkııık (main engine endurance) testinin başlaması için çapa ve ırgat testleri öncül kabul edilmiştir. Ayrıca uzun bir test olan ana makine dayanıklılık testi sırasında ses ölçüm (noise measurement) ve tatlı su jeneratörü (freshwater generator) testlerinin de yapılabileceği belirtilmiştir. Otomatik yavaşlama/makine durdurma (Automatic slow down/shut down) testinin yapılabilmesi için dayanıklılık testi öncül olarak kabul edilmiştir. Bundan sonra dümen (steering gear) testleri, $10^{\circ}$ ve $20^{\circ}$ zig-zag manevra testleri, hız, durma, tornistan (astern trial), dönme dairesi (turning circle) ve çarpışma durma (crash stop) testlerinin birbirlerini takip ederek yapılması planlanmıştır. Otomasyon (AUT-UMS (Automated machinery system-Unattended machinery space)) testin yapılmasının öncülü çarpışma durma testi olarak belirlenmiştir. Ayrıca otomasyon testi sırasında duman algılama testinin de yapılması düşünülmüştür. Bunun ardından alternatif sevk sistemi (AVM-APS (Availability of machinery- 
Alternative propulsion system)) testi gelmektedir. Ancak AVM-APS testinde geminin sevki şaft jeneratörü ile yapılacağından öncelikle şaft jeneratörü kontrollerinin yapılması gerekmektedir. Karartma (black out) testinin öncülü ise AVM-APS testi olarak belirlenmiştir. Bütün testlerin tamamlanması sonrasında yapılan toplantı ile geminin tersaneye dönüş süreci de başlamış olur.

\section{PERT Analizi}

Uzun soluklu projeler karmaşık süreçler içermektedir. Bu süreçleri yönetmek, özellikle gemi inşaatı alanında, oldukça meşakkatli olduğundan proje yönetimi konusunda programlar ve teknikler kullanmak kaçınılmaz olmaktadır. Örneğin bu tekniklerden birisi kritik yol metodudur (CPM). CPM'de faaliyet sürelerinin deterministik olduğu varsayılmaktadır. Gerçek hayatta aktivite süreleri genellikle deterministik değildir ancak eğer bir aktivite daha önceden tamamlanmışsa ve tekdüze bir faaliyet ise deterministik olarak kabul edilebilir. Kritik zincir metodu kısıtlar teorisi temeline dayanan bir proje yönetim tekniği olarak ortaya çıkmıştır. Bu teknikte proses üzerindeki darboğazların tespit edilerek bunların yok edilmesi ve aktivite sürelerindeki bollukların yerine projenin tümü için bir tampon süre belirlenmesi ve bunun proje boyunca izlenmesi esastır. Bu uygulama kapsamında kullanılan PERT tekniği de yapılacak olan faaliyetlerin sürelerinin olasılıklı olduğu durumlarda, projenin tamamlanması için gerekli sürenin ön görülmesinde yardımcı olabilmektedir. PERT, İngilizcedeki "Program Evaluation and Review Technique" ifadesinin kısaltması olarak karşımıza çıkmaktadır ve Türkçede "Program Değerlendirme ve Gözden Geçirme Tekniği" olarak da geçmektedir. PERT ile CPM benzer ağ yapısını kullanmakla beraber temel farkın faaliyet sürelerinin ele alınmasında ortaya çıktığı ifade edilebilir. Bu çalışmada stokastik faaliyet sürelerinden oluşan bir projenin planını elde etmek amaçlandığı için PERT kullanılmıştır.

\subsection{Ağ Diyagramı İçin Gerekli Verilerin Elde Edilmesi}

Bilindiği üzere PERT analizinde iyimser süre (optimistic time), muhtemel süre (most likely time) ve kötümser süre (pessimistic time) olmak üzere üç adet süre parametresi kullanılmaktadır. Bu süreler tecrübî olarak veya geçmiş verilerin işlenmesi ile belirlenebilir. Öte yandan PERT analizinde aktivite sürelerinin beklenen değeri ve standart sapmasını hesaplamak için Denklem 1 kullanılmaktadır (Nicolas and Styen, 2008).

$$
s b=\frac{i+4 m+k}{6}, \quad \sigma=\frac{k-i}{6}
$$

Burada $s b$ aktivite süresinin beklenen değerini, $\sigma$ ise standart sapmasını temsil etmektedir. Ayrıca i, m ve $k$ ise sırasıyla iyimser, muhtemel ve kötümser süre anlamına gelmektedir.

Bu çalışmada deneme seyri bir proje olarak ele alınmış ve ilgili aktiviteler öncüllük ardıllık ilişkileri ve kaynak kısıtları dikkate alınarak bir program dâhilinde sıralanmışlardır. Buna göre deneme seyrinde gerçekleştirilen aktiviteler Tablo 1'de verilmiştir. Burada görülen beklenen süre ve standart sapma değerleri Denklem 1'e göre hesaplanmıştır.

Bilindiği üzere aktivitelerin birbirleriyle olan ilişkileri dört şekilde ifade edilmektedir:

- "Tamamlanınca-Başla" (Finish-to-Start / FS): Öncül aktivite bittiği zaman ardıl aktivite başlar.

- “Tamamlanınca-Tamamla” (Finish-to-Finish / FF): Öncül aktivite tamamlandığında ardıl aktivite de tamamlanır. 
- "Başlayınca-Başla" (Start-to-Start / SS): Öncül aktivite başladığı zaman ardıl aktivite de başlar.

- "Başlayınca-Tamamla" (Start-to-Finish / SF): Bir aktivite başladığında diğer aktivite tamamlanır.

Tablo 1'de 2 numaralı aktivitenin öncül sütununda bulunan "1FF-15 dak" ifadesi 1 numaralı aktivitenin tamamlanmasından 15 dakika önce 2 numaralı aktivitenin tamamlanacağını göstermektedir. Öncül sütunundaki FS, FF, SS veya SF ifadelerinden biri bulunmayan ilişkiler için FS ilişkisi geçerlidir.

Tablo 1. Deneme seyri aktivitelerinin süre ve öncül-ardıl ilişki bilgileri

\begin{tabular}{|c|c|c|c|c|c|c|c|}
\hline$j$ & Aktivite & Öncül & $\begin{array}{l}\text { İyimser } \\
\text { süre }\end{array}$ & $\begin{array}{c}\text { Muhtemel } \\
\text { süre }\end{array}$ & $\begin{array}{c}\text { Kötümser } \\
\text { süre }\end{array}$ & $\begin{array}{c}\text { Beklenen } \\
\text { süre }\end{array}$ & Varyans \\
\hline 1 & Personelin gemiye çıkması & - & 45 dak & 60 dak & 90 dak & 62.5 dak & 56.3 dak \\
\hline 2 & Draft ölçümü & $1 \mathrm{FF}-15$ dak & 15 dak & 20 dak & 30 dak & 20.8 dak & 6.3 dak \\
\hline 3 & Başlangıç toplantısı & $1 ; 2$ & 20 dak & 30 dak & 45 dak & 30.8 dak & 17.4 dak \\
\hline 4 & Cayro pusula ayarları & $1 ; 2$ & 45 dak & 60 dak & 75 dak & 60 dak & 25 dak \\
\hline 5 & Ana makine ayarları & $1 ; 2$ & 45 dak & 60 dak & 90 dak & 62.5 dak & 56.3 dak \\
\hline 6 & Navigasyon ekipman testi & $1 ; 2$ & 20 dak & 30 dak & 45 dak & 30.8 dak & 17.4 dak \\
\hline 7 & MDO'dan HFO'ya geçiş & 5 & 15 dak & 20 dak & 30 dak & 20.8 dak & 6.3 dak \\
\hline 8 & Baş itici testi (Sancak) & 7 & 30 dak & 45 dak & 60 dak & 45 dak & 25 dak \\
\hline 9 & Kazan kontrolleri ve alarm testleri & 3 & 20 dak & 30 dak & 40 dak & 30 dak & 11.1 dak \\
\hline 10 & Baş itici testi (ískele) & 8 & 20 dak & 30 dak & 40 dak & 30 dak & 11.1 dak \\
\hline 11 & Yakıt hazırlama modül testi ve alarmları & 7 & 20 dak & 30 dak & 45 dak & 30.8 dak & 17.4 dak \\
\hline 12 & Çapa ve ırgat testi (Sancak) & 10 & 20 dak & 30 dak & 40 dak & 30 dak & 11.1 dak \\
\hline 13 & Separatör testi ve alarmları & $3 ; 9$ & 20 dak & 30 dak & 45 dak & 30.8 dak & 17.4 dak \\
\hline 14 & Çapa ve ırgat testi (İskele) & 12 & 20 dak & 30 dak & 40 dak & 30 dak & 11.1 dak \\
\hline 15 & Ses ölçüm testi & $16 S S$ & 45 dak & 60 dak & 90 dak & 62.5 dak & 56.3 dak \\
\hline 16 & Ana makine dayanıklılık testi & 14 & 240 dak & 270 dak & 300 dak & 270 dak & 100 dak \\
\hline 17 & Tatlı su jeneratörü testi & $16 S S$ & 30 dak & 45 dak & 60 dak & 45 dak & 25 dak \\
\hline 18 & Otomatik yavaşlama/makine durdurma testi & 16 & 30 dak & 45 dak & 60 dak & 45 dak & 25 dak \\
\hline 19 & Çift pompa dümen testi & 18 & 10 dak & 15 dak & 20 dak & 15 dak & $2.8 \mathrm{dak}$ \\
\hline 20 & Tek pompa dümen testi 1 & 19 & 10 dak & 15 dak & 25 dak & 15.8 dak & 6.3 dak \\
\hline 21 & Tek pompa dümen testi 2 & 20 & 10 dak & 15 dak & 25 dak & 15.8 dak & 6.3 dak \\
\hline 22 & Zig-zag manevra testi $\left(10^{\circ} / 10^{\circ}\right)$ & 21 & 20 dak & 30 dak & 45 dak & 30.8 dak & 17.4 dak \\
\hline 23 & Zig-zag manevra testi $\left(20^{\circ} / 20^{\circ}\right)$ & 22 & 20 dak & 30 dak & 45 dak & 30.8 dak & 17.4 dak \\
\hline 24 & Hız testi & 23 & 30 dak & 45 dak & 60 dak & 45 dak & 25 dak \\
\hline 25 & Durma testi & 24 & 20 dak & 30 dak & 45 dak & 30.8 dak & 17.4 dak \\
\hline 26 & Tornistan testi & 25 & 20 dak & 30 dak & 45 dak & 30.8 dak & 17.4 dak \\
\hline 27 & İskele dönme dairesi testi & 26 & 20 dak & 30 dak & 45 dak & 30.8 dak & 17.4 dak \\
\hline 28 & Sancak dönme dairesi testi & 27 & 20 dak & 30 dak & 45 dak & 30.8 dak & 17.4 dak \\
\hline 29 & Çarpışma durma testi & 28 & 20 dak & 30 dak & 45 dak & 30.8 dak & 17.4 dak \\
\hline 30 & Otomasyon testi (AUT-UMS) & 29 & 360 dak & 400 dak & 460 dak & 403.3 dak & 277.8 dak \\
\hline 31 & Duman algılama testi & $30 \mathrm{ss}$ & 45 dak & 60 dak & 75 dak & 60 dak & 25 dak \\
\hline 32 & AVM-APS öncesi şaft jeneratörü kontrolü & 30 & 15 dak & 20 dak & 30 dak & 20.8 dak & 6.3 dak \\
\hline 33 & Alternatif sevk sistemi testi (AVM-APS) & 32 & 60 dak & 75 dak & 90 dak & 75 dak & 25 dak \\
\hline 34 & Karartma testi & 33 & 20 dak & 30 dak & 45 dak & 30.8 dak & 17.4 dak \\
\hline 35 & Karar toplantısı & 34 & 20 dak & 30 dak & 45 dak & 30.8 dak & 17.4 dak \\
\hline 36 & HFO'dan MDO'ya geçiş & 34 & 15 dak & 20 dak & 30 dak & 20.8 dak & 6.3 dak \\
\hline 37 & Tersaneye dönüş & $35 ; 36$ & 45 dak & 60 dak & 90 dak & 62.5 dak & 56.3 dak \\
\hline
\end{tabular}




\subsection{Ağ Diyagramının Oluşturulması}

Deneme seyrinin tamamlanma süresinin beklenen değeri ve standart sapmasını belirleyebilmek için kritik yolun tespit edilmesi gerekmektedir. Bilindiği üzere bolluk süresi sıfır olan aktivite silsilesi kritik yolu göstermektedir. Şekil 1'de deneme seyrinin ağ diyagramı verilmiştir. Burada görülen kırmızı renkli aktiviteler kritik yolu göstermektedir.

Deneme seyrinin tamamlanma süresinin beklenen değerini bulmak için kritik yol üzerinde bulunan aktivitelerin Denklem 1 vasıtasıyla hesaplanan beklenen değerlerinin toplamı alınır. Benzer şekilde deneme seyrinin tamamlanma süresinin standart sapmasını hesaplamak için de kritik yol üzerinde bulunan aktivitelerin Denklem 1 vasıtasıyla hesaplanan standart sapma değerlerinin toplamı alınır. Buna göre deneme seyrinin tamamlanma süresinin beklenen değeri 1526.2 dakika, standart sapması ise 29.4 dakika olarak belirlenmiştir.

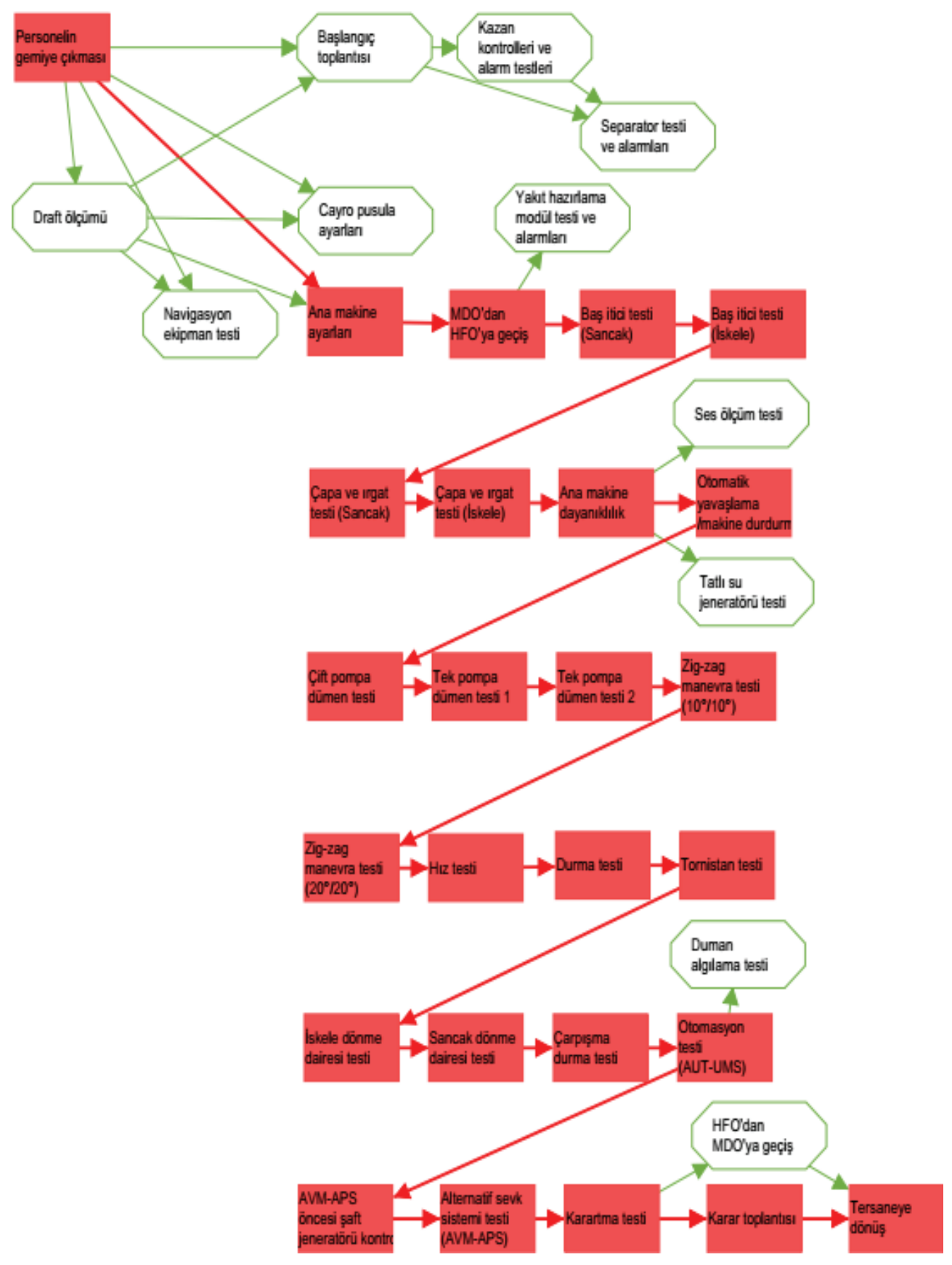

Şekil 1. Deneme seyri ağ diyagramı 


\section{4. Çıktıların İncelenmesi}

\subsection{Seyir Süresi Olasılıklarının Belirlenmesi}

PERT analizinde projenin tamamlanma süresi normal dağılım ile ifade edilir. Bu sayede hedeflenen bir tamamlanma süresinin olasılığı tespit edilebilmektedir (Nicolas and Styen, 2008). Bu amaçla öncelikle hedeflenen tamamlanma süresi standart normal değişkene çevrilir daha sonra z-tablosu yardımıyla ilgili olasılık değeri hesaplanır (Denklem 2).

$$
z=\frac{S h-S b}{\sigma}
$$

Burada z standart normal değişkeni, Sh tüm deneme seyri için hedeflenen tamamlanma süresini, $\mathrm{Sb}$ tüm deneme seyri için tamamlanma süresinin beklenen değerini, $\sigma$ ise tüm deneme seyri için standart sapmayı simgelemektedir. Tablo 2'de farklı tamamlanma sürelerinin bu şekilde hesaplanan olasılıkları verilmiştir. Burada 1440 dakika 24 saate yani tam bir güne denk gelmektedir. Buna göre bu çalışmada kullanılan bilgiler ışığında deneme seyrinin 1440 dakika veya daha az bir sürede yani en fazla bir günde bitme olasılığı oldukça düşük çıkmaktadır (\%0.2). Bir önceki bölümde hesaplanan beklenen değer 1526.2 dakika olduğundan bu değere yaklaştıkça olasılık değeri de \%50'ye doğru yaklaşmaktadır. Dolayısıyla deneme seyrinin 1470 dakika veya daha kısa bir sürede bitme olasılığı \%3; en fazla 1500 dakikada bitme olasıı̆ı̆ı \%19 olarak hesaplanmıştır. Bundan sonra verilen değerler beklenen değerden yüksek olduğu için olasılık değeri buna paralel olarak \%50'nin üzerindedir ve tedricen artmaya devam etmektedir. Bu bağlamda deneme seyrinin 1530 dakika veya daha kısa bir sürede bitme olasılığı \%55, en fazla 1560 dakika sürme olasılığı \%87, 1590 dakikadan daha az sürme olasılı̆̆ı ise \%98 olarak tespit edilmiştir.

Tablo 2. Deneme seyrinin farklı tamamlanma süreleri için olasılık değerleri

\begin{tabular}{|c|c|c|}
\hline $\begin{array}{c}\text { Hedeflenen tamamlanma } \\
\text { süresi (dakika) }\end{array}$ & $\mathbf{z}$ değeri & ihtimal \\
\hline 1440 & -2.93 & $0.2 \%$ \\
\hline 1470 & -1.91 & $3 \%$ \\
\hline 1500 & -0.89 & $19 \%$ \\
\hline 1530 & 0.13 & $55 \%$ \\
\hline 1560 & 1.15 & $87 \%$ \\
\hline 1590 & 2.17 & $98 \%$ \\
\hline
\end{tabular}

\subsection{Kaynak Bazlı İş Analizleri}

Kaynak kullanımına bakıldı̆ında kaynak kısıtından dolayı sadece "Separatör testi ve alarmları" aktivitesinin bir miktar ötelendiği görülmektedir. Normalde bu aktivite "Başlangıç toplantısı"ndan sonra başlayabilir ancak "Armatör temsilcisi_Mak" kaynağı yetmediğinden dolayı öncül olarak aynı kaynağı kullanan "Kazan kontrolleri ve alarm testleri" de eklenmiştir. "Separatör testi ve alarmları" aktivitesi kritik yol üzerinde bulunmadığından dolayı bu öteleme toplam seyir süresi üzerine bir etki yapmamıştır.

Deneme seyrinde kullanılan kaynaklarla alakalı bazı özet bilgiler Tablo 3'te verilmiştir. Kaynak kodu ilgili kaynağı kısaca belirten bir simgedir. Kaynak adedi ilgili kaynaktan deneme seyrine kaç adet katıldığını göstermektedir. $s b_{j}, j$ aktivitesinin tamamlanma süresinin beklenen değeri; $I$, toplam kaynak sayısı; $J$, toplam aktivite sayısı; $k_{i, j}$ ise $i$ kaynağından $j$ aktivitesinde kullanılan adedi göstermek üzere $i$ kaynağına düşen toplam iş miktarı $\left(W_{i}\right)$ Denklem 3 ile hesaplanır. 


$$
W_{i}=\sum_{j=1}^{J}\left(s b_{j} k_{i, j}\right), i=1,2, \ldots, I
$$

Tablo 3. Deneme seyrinde kullanılan kaynak bilgileri

\begin{tabular}{lcccccc}
\hline $\boldsymbol{i}$ & Kaynak adı & $\begin{array}{c}\text { Kaynak } \\
\text { kodu }\end{array}$ & $\begin{array}{c}\text { Kaynak } \\
\text { adedi } \\
\text { (Adam) }\end{array}$ & $\begin{array}{c}\text { Kaynağa düşen iş } \\
\text { miktarı }\left(W_{i}\right) \\
\text { (AdamDakika) }\end{array}$ & $\begin{array}{c}\text { Birim kaynak başına } \\
\text { iş miktarı (Dakika) }\end{array}$ & $\begin{array}{c}\text { Birim kaynak } \\
\text { kullanım oranı }\end{array}$ \\
\hline $\mathbf{1}$ & Klas sörveyörü & KS & 2 & 1672 & 836 & $55 \%$ \\
$\mathbf{2}$ & Armatör temsilcisi_Güv & ATG & 2 & 1504 & 752 & $49 \%$ \\
$\mathbf{3}$ & Armatör temsilcisi_Mak & ATM & 2 & 1475 & 738 & $48 \%$ \\
$\mathbf{4}$ & İşçi_Güv & IG & 10 & 1921 & 192 & $13 \%$ \\
$\mathbf{5}$ & İşi_Mak & iM & 10 & 2472 & 247 & $16 \%$ \\
$\mathbf{6}$ & Üretimci & Ü & 5 & 2446 & 489 & $32 \%$ \\
$\mathbf{7}$ & Kaliteci & K & 3 & 1784 & 595 & $39 \%$ \\
$\mathbf{8}$ & Servisçi_AnaMak & SAM & 1 & 62 & 62 & $4 \%$ \\
$\mathbf{9}$ & Servisçi_Cayro & SC & 1 & 60 & 30 & $4 \%$ \\
$\mathbf{1 0}$ & Servisçi_Kazan & SK & 1 & 30 & 62 & $2 \%$ \\
$\mathbf{1 1}$ & Servisçi_Ses & SS & 1 & 62 & 45 & $4 \%$ \\
$\mathbf{1 2}$ & Servisçi_TatlıSu & STS & 1 & 45 & 96 & $3 \%$ \\
$\mathbf{1 3}$ & Servisçi_ŞaftJen & SŞ」 & 1 & 96 & - & $6 \%$ \\
\hline
\end{tabular}

Kaynağa düşen iş miktarına göre kaynaklar incelendiğinde işi en fazla olan kaynak türü "İşçi_Mak", işi en az olan kaynak türü ise "Armatör temsilcisi_Mak" olarak belirlenmiştir. En yüksek birim kaynak kullanım oranı "Klas sörveyörü" kaynağında iken en düşük oran ise "Iş̧̧i_Güv" kaynağındadır.

Birim kaynak kullanım oranı, birim kaynak başına düşen iş miktarının deneme seyri süresine bölünmesi ile hesaplanmıştır. Farklı ekipmanların servis personelleri kendileri ile alakalı testin tamamlanmasının artından genellikle seyirden ayrılırlar, bu bakımdan bunların birim kullanım oranları oldukça düşük çıkmaktadır. Burada servis personelinden ziyade asıl odaklanılması gereken kaynaklar seyir boyunca gemide bulunanlardır. Örneğin "Klas sörveyörü" deneme seyrine genelde 2 kişi olarak katılmaktadır. Bunların seyir süresince birçok teste iştirak etmeleri gerektiğinden birim kaynak başına iş miktarı ve birim kaynak kullanım oranı en yüksek değeri almıştır. Bunun yanı sıra "İş̧i_Mak" ve "İş̧̧i_Güv" kaynakları için ise kaynağa düşen iş miktarları $\left(W_{i}\right)$ en yüksek değerler olmuştur. Ancak seyre katılan kişi sayıları daha yüksek olduğundan birim kaynak başına iş miktarı ve birim kaynak kullanım oranı daha düşük çıkmıştır. İşcilerin seyre katılım sayıları dikkate alınırken çalışma süreleri ve acil durumda gerekli müdahalenin yapılabilmesi gibi şartlar da dikkate alınmıştır.

\subsection{Aktivite Bazlı Iş Analizleri}

Deneme seyrinde gerçekleştirilen aktivitelerin sahip olduğu iş miktarları bu bölümde incelenmiştir. $j$ aktivitesinin toplam iş miktarı $\left(W_{j}\right)$ Denklem 4 ile hesaplanır.

$$
W_{j}=s b_{j} \sum_{i=1}^{I}\left(k_{i, j}\right), j=1,2, \ldots, J
$$

Tablo 4'te bu şekilde hesaplanan $W_{j}$ değerleri ve her bir aktivitede kullanılan kaynak adedi görülmektedir. Buradaki "Kaynaklar sütununda" her bir aktivitede hangi kaynağın kullanıldığı kaynak kodları vasıtasıyla verilmiştir. Bu sütunda kaynak kodu yanında parantez içinde verilen değer o 
kaynaktan kaç adet bulunduğunu göstermektedir. Yanında hiçbir sayı bulunmayan kaynaklardan bir tane kullanıldığı anlaşılmalıdır. Örneğin üçüncü aktivitede (Başlangıç toplantısı) ATG, ATM, $K$ ve KS kaynaklarında bir adet, Ü kaynağından ise 2 adet kullanılmıştır.

Tablo 4. Aktivite bazında iş ve kaynak miktarları.

\begin{tabular}{|c|c|c|c|c|}
\hline$j$ & Aktivite & $\begin{array}{c}\text { iş }\left(W_{j}\right) \\
\text { (AdamDakika) }\end{array}$ & $\begin{array}{l}\text { Kaynak adedi } \\
\text { (Adam) }\end{array}$ & Kaynaklar \\
\hline 1 & Personelin gemiye çıkması & - & - & - \\
\hline 2 & Draft ölçümü & 63 & 3 & ATG;KS;K \\
\hline 3 & Başlangıç toplantısı & 186 & 6 & ATG;ATM;K;KS; ̈̈(2) \\
\hline 4 & Cayro pusula ayarları & 180 & 3 & SC;IG;K \\
\hline 5 & Ana makine ayarları & 248 & 4 & SAM;ATM;Ü;iM \\
\hline 6 & Navigasyon ekipman testi & 124 & 4 & IG;ATG;K;KS \\
\hline 7 & MDO'dan HFO'ya geçiş & 42 & 2 & iM;Ü \\
\hline 8 & Baş itici testi (Sancak) & 180 & 4 & Ü;ATG;KS;K \\
\hline 9 & Kazan kontrolleri ve alarm testleri & 150 & 5 & ATM;KS;Ü;K;SK \\
\hline 10 & Baş itici testi (İskele) & 120 & 4 & ATG;K;KS;Ü \\
\hline 11 & Yakıt hazırlama modül testi ve alarmları & 155 & 5 & KS;ATM;Ü;iM;K \\
\hline 12 & Çapa ve ırgat testi (Sancak) & 330 & 11 & $\operatorname{ATG}(2) ; \mathrm{IG}(3) ; \mathrm{K}(2) ; \mathrm{KS}(2) ; \ddot{U}(2)$ \\
\hline 13 & Separatör testi ve alarmları & 124 & 4 & Ü;ATM;K;iM \\
\hline 14 & Çapa ve ırgat testi (ískele) & 330 & 11 & $\operatorname{ATG}(2) ; \mathrm{IG}(3) ; \mathrm{K}(2) ; \mathrm{KS}(2) ; \mathrm{Ü}(2)$ \\
\hline 15 & Ses ölçüm testi & 310 & 5 & SS;ATG;KS;K;Ü \\
\hline 16 & Ana makine dayanıklılık testi & 2430 & 9 & ATG;ATM;K;KS;Ü(2);iG(2);iM(3) \\
\hline 17 & Tatlı su jeneratörü testi & 225 & 5 & STS;ATM;iM;Ü(2) \\
\hline 18 & $\begin{array}{l}\text { Otomatik yavaşlama /makine durdurma } \\
\text { testi }\end{array}$ & 270 & 6 & ATM;ATG;iM(2);K;KS \\
\hline 19 & Çift pompa dümen testi & 120 & 8 & ATG;ATM;IM(2);K(2);KS(2) \\
\hline 20 & Tek pompa dümen testi 1 & 128 & 8 & ATG;ATM;IM(2);K(2);KS(2) \\
\hline 21 & Tek pompa dümen testi 2 & 128 & 8 & ATG;ATM;IM(2);K(2);KS(2) \\
\hline 22 & Zig-zag manevra testi $\left(10^{\circ} / 10^{\circ}\right)$ & 186 & 6 & ATG;K;KS;Ü(2);ATM \\
\hline 23 & Zig-zag manevra testi $\left(20^{\circ} / 20^{\circ}\right)$ & 186 & 6 & ATG;K;KS;Ü(2);ATM \\
\hline 24 & Hız testi & 270 & 6 & ATG;K;KS;Ü(2);ATM \\
\hline 25 & Durma testi & 186 & 6 & ATG;K;KS;Ü(2);ATM \\
\hline 26 & Tornistan testi & 186 & 6 & ATG;K;KS;Ü(2);ATM \\
\hline 27 & İskele dönme dairesi testi & 186 & 6 & ATG;K;KS;Ü(2);ATM \\
\hline 28 & Sancak dönme dairesi testi & 186 & 6 & ATG;K;KS;Ü(2);ATM \\
\hline 29 & Çarpışma durma testi & 341 & 11 & ATG;K;KS;Ü(2);ATM;iM(3);í(2) \\
\hline 30 & Otomasyon testi (AUT-UMS) & 4030 & 10 & ATG;ATM;iG(2);iM(2);K;KS;Ü(2) \\
\hline 31 & Duman algılama testi & 540 & 9 & ATM;iM(3);iG(3);K;KS \\
\hline 32 & AVM-APS öncesi şaft jeneratörü kontrolü & 126 & 6 & SŞ」;Ü(2);ATM;K;iM \\
\hline 33 & Alternatif sevk sistemi testi (AVM-APS) & 825 & 11 & ATG;ATM;iM(5);K;KS;SŞJ;Ü(2) \\
\hline 34 & Karartma testi & 310 & 10 & ATG;ATM;iG(2);iM(2);K;KS;Ü(2) \\
\hline 35 & Karar toplantısı & 186 & 6 & ATG;ATM;K;KS;Ü(2) \\
\hline 36 & HFO'dan MDO'ya geçiş & 42 & 2 & iM;Ü \\
\hline \multirow[t]{2}{*}{37} & Tersaneye dönüş & - & - & - \\
\hline & Toplam & 13629 & - & - \\
\hline
\end{tabular}

Toplam iş miktarına bakılacak olursa Tablo 2'de hesaplanan toplam iş miktarı ile aynı olduğu görülmektedir ki zaten bu şekilde olması gerekir. En fazla işin "Otomasyon testi (AUT-UMS)" 
aktivitesinde olduğu görülmektedir. Bu aktivitenin hem süresi uzun hem de kullanılan kaynak miktarı fazla olduğundan sonucun bu şekilde çıkması normaldir. En az iş ise birbirinin tersi olan "MDO'dan HFO'ya geçiş" ve "HFO'dan MDO'ya geçiş" aktivitelerinde hesaplanmıştır. Öte yandan en fazla kaynak adedi kullanılan aktivitelere bakıldığında bunların "Çapa ve ırgat testi (Sancak)", "Çapa ve ırgat testi (İskele)", "Çarpışma durma testi" ve "Alternatif sevk sistemi testi (AVM-APS)" olduğu görülmektedir. Diğer taraftan en az kaynak adedi kullanan aktiviteler ise "MDO'dan HFO'ya geçiş" ve "HFO'dan MDO'ya geçiş" olarak belirlenmiştir. Tablo 4' te görüldügüu üzere ilk ve son aktiviteler sırasıyla gemiye gidiş ve gemiden dönüş olduğu için bunlara herhangi bir kaynak ataması yapılmamış ve dolayısıyla bu aktiviteler için iş hesaplanmamıştır.

\section{Sonuçlar}

Deneme seyri bir geminin armatöre teslim edilmeden önceki son testlerinden oluşmaktadır. Ayrıca bu seyir kesintisiz olarak çoğu zaman bir günden fazla sürdüğü için stresin yoğun olarak yaşandığı bir üretim aşaması olarak düşünülebilir. Bu sürecin daha kolay gerçekleştirilebilmesi için önceden planlamasının yapılması gerektiği değerlendirilmektedir. Bu çalışmada bir geminin deneme seyri sırasında yapılacak olan testler için bir planlama oluşturulmuştur. Bu alanda PERT analizinin yapılması ile literatüre katkı yapmaktadır. Gerçek bir deneme seyrinden elde edilen bilgiler yardımı ile bir aktivite listesi elde edilmiş ve bu listedeki testlerin tamamı bir proje olarak kabul edilmiştir. Deneme seyri sürecince aktivite sürelerinini kesin bir şekilde belirlenmesi zor olduğundan aktivite süreleri yaklaşık olarak belirlenmiştir. PERT analizinde stokastik bir model bulunması sayesinde aktivite sürelerindeki belirsizlik çalışmaya yansıtılmıştır. Ayrıca burada ele alınan deneme seyrinin bir kimyasal tanker gemisine ait olduğu unutulmamalıdır. Bu projede hangi testin kimler tarafından yapılacağı belirlenmiş ve testlere kaynak ataması yapılmıştır. Bunun yanı sıra testlerin hangi sıra ile yapılacağı ve aynı zaman dilimi içerisinde birbirlerini etkilemeden yapılabilecek testler belirlenmiştir. Elde edilen ağ diyagramı yardımı ile kritik yol tespiti yapılmıştır. Bu sayede 37 madde halinde listelenen aktivitelerden 26 tanesinin kritik aktivite olduğu görülmüştür. Ayrıca PERT uygulaması ile bütün aktivite sürelerinin beklenen değeri ve standat sapması hesaplanmıştır. Kritik yol üzerinde bulunan 26 aktivite projenin toplam süresini vermektedir. Bu aktivite sürelerinin beklenen değerleri toplandığında projenin tamamlanma süresinin beklenen değerinin 1526.2 dakika, standart sapmasının ise 29.4 dakika olduğu görülmüştür. Bunun yanı sıra farklı olasılık değerleri için z tablosu yardımı ile farklı seyir sürelerinin olasılıkları hesaplanmıştır. Burada, deneme seyrinin 1440 dakika ve daha kısa sürede bitme olasılığ \%0.2 ile çok düşük, 1590 dakika ve daha kısa sürede bitme olasılığı \%98 ile çok yüksek olarak belirlenmiştir.

Hazırlanan deneme seyri çizelgesinde kaynağa düşen iş miktarı, birim kaynak başına düşen iş miktarı ve birim kaynak kullanım oranı hesaplanmıştır. "İş̧̧i_Güv" ve "İşçi_Mak" kaynaklarında kaynağa düşen iş miktarı yüksek çıkmasına rağmen birim kaynak kullanım oranının kişi sayısa bağlı olarak düşük olduğu görülmüştür. Bunun yanısıra aktivite bazlı iş miktarları da hesaplanmış ve liste halinde gösterilmiştir. En fazla işin "Otomasyon testi (AUT-UMS)" aktivitesi için hesaplandığı, en az işin ise "MDO'dan HFO'ya geçiş" ve "HFO'dan MDO'ya geçiş" aktivitelerinde olduğu görülmüştür. Daha sonra yapılacak olan çalışmalarda farklı tipte olan gemilere ait deneme seyir programları bu uygulama kapsamına alınabilir. Bunun yanı sıra daha karmaşık ve uzun soluklu testlerin yapıldığı savaş gemilerinin deneme seyir süreçleri benzer şekilde incelenerek belirli bir seyir programı elde edilmeye çalışabilir. 


\section{Referanslar}

Abdel-latif, S., Abdel-geliel, M. ve Zakzouk, E.,E. (2013). Simulation of Ship Maneuvering Behavior Based on the Modular Mathematical Model, 21st Mediterranean Conference on Control \& Automation, June, Crete, Greece, 94-99.

Akan, E. ve Bayar, S. (2021). “Interval type-2 fuzzy program evaluation and review technique for project management in shipbuilding", Ships and Offshore Structures, 1-19, https://doi.org/10.1080/17445302.2021.1950350

Aktan, N. (1995). Gemilerin Liman ve Deniz Tecrübelerinin Planlanması, Yüksek Lisans Tezi, İstanbul Teknik Üniversitesi, Fen Bilimleri Enstitüsü, İstanbul.

Aslıyüksek, M. (2013). Türkiye Özel Sektör Tersanelerinde Askeri Gemi İnşa Projeleri Test ve Tecrübe Yönetimi, Yüksek Lisans Tezi, İstanbul Teknik Üniversitesi, Fen Bilimleri Enstitüsü, İstanbul.

Doğan, ÜB. ve Helvacioğlu ï. (2017). "Customized project management methods and their applications in shipbuilding projects", GiDB Dergi. Vol 10, 3-20.

Fulser, G. (2012). Askeri ve Sivil Gemi İnşa Sürecinde Test ve Kabul Faaliyetlerinin Planlaması ve Optimizasyonu, Yüksek Lisans Tezi, İstanbul Teknik Üniversitesi, Fen bilimleri Enstitüsü, İstanbul.

Genç, Y. ve Özkök, M. (2020), "Simulation-Based Optimization of the Sea Trial on Ships”, Journal of ETA Maritime Science, Vol. 8(4), 274-285.

Goldratt, E., M., Cox, J. (1992). The Goal: A Process of Ongoing Improvement, Second Revised Edition, North River Press.

Hwang In H., Kim Y., Lee D. K., Shin J. G. (2014), “Automation of block assignment planning using a diagram-based scenario modeling method", Int. J. Nav. Archit. Ocean Eng., Vol. 6, 162-174.

IMO Circular MSC/Circ. (2002). Explanatory Notes to the Standards for Ship Maneuverability, International Maritime Organization, 1053.

Kafalı M., Özkök M. (2015), “Evaluation of shipyard selection criteria for shipowners using a fuzzy technique", Journal of Marine Engineering \& Technology, Vol. 14(3), 146-158.

Kafalı M., Eren Ş., Helvacıoğlu İ. H. and Ünsan Y. (2021). A study on sub work package determination methodology for shipyards, Ships and Offshore Structures, 1-11. doi: 10.1080/17445302.2021.1943848.

Lee J. M., Jeong Y-K., Woo J. H. (2018). Development of an Evaluation Framework of Production Planning for the Shipbuilding Industry. International Journal of Computer Integrated Manufacturing, Vol. 31(9), 831-847.

Nicholas, J.M. and Steyn, H. (2008). "Project management for business, engineering, and technology: Principles and practice", Elsevier, Canada, Ed 3.

Song, Y.J., Woo, J.H., \& Shin, J.G. (2011). Research on systematization and advancement of shipbuilding production management for flexible and agile response for high value offshore platform. International Journal of Naval Architecture and Ocean Engineering, 3(3), 181-192.

Turan, E. and Asar, R. 2020. "Ship repair and maintenance management: application of PERT analysis on a tanker vessel. Journal of Ship Production and Design. Vol. 36(3): 181-188. 
Wang, H., Guo, Y., Liang, X., \& Yi., H. (2019). A function-oriented quality control method for shipbuilding. Ships and Offshore Structures, 14(2), 220-228. 